\title{
Necesidad de Equilibrio Fiscal entre Transferencias Intergubernamentales y Competencias Tributarias de los Estados en Venezuela
}

\author{
Fuenmayor, Jennifer ${ }^{\star}$
}

\section{Resumen}

Este articulo intenta analizar la estructura de los ingresos de los estados en Venezuela para el penodo comprendido 1989-1999, además de examinar la Constitución de 1999 en materia de ingresos para los estados. Para ello se realizó una investigación de carácter descriptivo, utilizándose como fuente principal para dicho estudio las estadísticas de la finanzas públicas, además de la normaliva jurídica respectiva, así como también la consulta bibliográfica con la finalidad de extraer la información documental. Los resultados revelan que los estados dependen altamente de las transferencias intergubernamentales. No obstante, la fuente principal de financiamiento de los estados continúa siendo el Situado Constitucional, por lo que la estructura de financiamiento de los estados registra un pronunciado sesgo hacia estas transterencias en perjuicio de la generación de ingresos propios. En este sentido se plantea que se deben ceder a éstos ciertos tribulos de mayor impacto fiscal y, recaudatorio, pensando también en la figura de la coparticipación tributaria entre el Poder Nacional y los estados.

Palabras clave: Descentralización Fiscal, Transferencias Intergubernamentales, Ingresos Propios, Constitución de 1999, Competencias Tributarias, Estados, Venezuela.

\section{Recibido: 00-06-30, Aceptado: 01-03-25}

* Economista, Maestría en Ciencia Política y Derecho Pủblico, mención Ciencia Politica. Cursante del Doctorado en Ciencias Sociales. Investigadora del Instituto de Investigaciones de la Facultad de Ciencias Económicas y Sociales de LUZ. Profesora del postgrado en la materia finanzas estadales y municipales. Acreditada en el Programa de Promoción al Investigador (PPI) del Conicit E-mail: jifuenmayo@ terra.com.ve 


\title{
The Need For Fiscal Equilibrium Between Inter-Governmental Transfers and Tributary Competence on a State Level in Venezuela
}

\begin{abstract}
This article analyzes the structure of state income in Venezuelan States over the period 1989-1999, and examines the 1999 Constitution in reference to state income. In order to do this a descriptive analysis was employed utilizing as a principal source of information public finance statistics as well as the respective judicial norms and bibliographical material in order to locate documentary information. The results reveal that States depend heavily on inter-govemmental transfers. However the principal source of state financing continues to be the national constitutional state allowance, and for this reason state finance structures heavily register a bias towards this type of transfer instead of generating their own incomes. In the face of this reality, we propose that certain taxation of high fiscal and collective impact be ceded to states within the framework of co-participation in taxation between national and state powers.
\end{abstract}

Key words: Fiscal de-centralization, intergovernmental transfers, income, 1999 Constitution, taxation authority, states, Venezuela.

\section{Introducción}

En Venezuela las fuentes de mayor potencial recaudatorio constituyen potestad del gobierno central, estas son: Impuesto Sobre La Renta (ISLR), ingresos por la actividad petrolera, por concepto de renta de hidrocarburos, Impuesto al valor agregado (IVA), renta de licores, cigarrillos, impuestos derivados de petróleo, tasas, impuestos de Importación y de otras actividades. Por lo tanto su potencial recaudatorio es bastante amplio, con relación al potencial de los estados.

El panorama para los estados luce diferente y se verifica en la Constitución de 1999, donde sólo se le asigna la parte residual, es decir, lo que no le corresponde al Poder Central, además de las Competencias Exclusivas contempladas ya en la Ley Orgánica de Descentralización (LOD) en su artículo 11, estas son : puente, puerto, aeropuerto, papel sellado, salinas, piedras no preciosas, vías estadales e interestadales. Pero a pesar de ello, estos ingresos han sido poco significativos para los estados y están catalogados de bajo impacto fiscal, ya que su recaudación asi lo demuestra, por no llegar a representar ni el 10 por ciento dentro de la estructura de los ingresos de los Estados, además de estar seriamente comprometidos en su mayoría en el mantenimiento de los servicios anteriormente mencionados. Por lo tanto las leyes en esta materia no le permiten a los estados cierto grado de flexibilidad para generar estos recursos, sino que éstos están atados principalmente a los recursos del Situado Constitucional.

El mencionado mecanismo de financiamiento se constituye en la transferencia intergubernamental de mayor importancia para los estados. El mismo depende de los ingresos del petróleo por lo que dificulta la búsqueda de un nuevo sistema fiscal más acorde con los cambios en el sistema económico e institucional. 
En la década pasada se crearon dos nuevos mecanismos de transferencias intergubernamentales, uno de ellos es el Fondo Intergubernamental para la Descentralización (FIDES), creado mediante decreto-ley en 1993 por el Presidente en transición Ramón J. Velásquez y el otro es el Sistema de Asignaciones Económicas Especiales para Estados Mineros y Petroleros (LAEE), aprobado en 1996 en el gobiemo de Rafael Caldera. Estos mecanismos de financiamiento se diferencian del situado constitucional en que están condicionados a la previa presentación y aprobación de proyectos de inversión para poder asi acceder a estos recursos.

Con la puesta en funcionamiento de los dos mecanismos de financiamiento antes mencionados se da un desequilibrio o desproporción en la estructura de ingresos de los estados, donde los mismos dependen altamente de los recursos por la vía de estas transferencias intergubernamentales en perjuicio de la generación de sus ingresos propios. Lo anterior se ve reflejado en la disminución de la dependencia de los recursos por la vía del situado constitucional para los años 1997 y 1998 respectivamente y a un aumento de la dependencia por los recursos del FIDES y la LAEE.

Queda de esta forma implícito el objetivo de la investigación, como lo es el de analizar la estructura de los ingresos de los estados para verificar dicho desequilibro.

\section{Las finanzas públicas del gobierno central}

En la Tabla 1 se muestra las finanzas públicas del gobierno central y se observa que, las principales fuentes tributarias están en potestad de este nivel de gobierno.

\section{Tabla 1}

Estructura de los Ingresos Ordinarios del Gobierno General' (Porcentajes)

\begin{tabular}{lrrrrrrrr}
\hline & 1990 & 1991 & 1992 & 1993 & 1994 & 1995 & 1996 & 1997 \\
\hline Total de Ingresos Ordinarios & 100 & 100 & 100 & 100 & 100 & 100 & 100 & 100 \\
Ingresos Petroleros & 82,9 & 79,9 & 67,6 & 60,2 & 52,4 & 44,7 & 58,3 & 54,5 \\
Ingresos no Petroleros & 17,1 & 20,1 & 32,4 & 39,8 & 47,6 & 55,3 & 41,7 & 45,5 \\
Impuestos Directos & 6,0 & 5,7 & 8,8 & 13,6 & 13,3 & 12,2 & 9,3 & 9,3 \\
ISRL & 5,9 & 5,5 & 8,7 & 13,4 & 13,1 & 12,0 & 9,2 & 9,2 \\
Impuestos Indirectos & 6,4 & 10,1 & 18,2 & 22,9 & 32,1 & 41,1 & 30,4 & 34,1 \\
Renta Aduanera & 3,1 & 6,4 & 10,4 & 9,7 & 8,9 & 8,0 & 6,6 & 6,7 \\
IVA /CSVM & - & - & - & 3,7 & 15,7 & 26,5 & 19,7 & 20,7 \\
Otros Indirectos & 3,3 & 3,7 & 7,8 & 9,5 & 7,5 & 6,6 & 4,1 & 6,74 \\
Otros Ingresos no Petroleros & 4,7 & 4,3 & 5,4 & 3,3 & 2,2 & 2,0 & 2,0 & 2,1 \\
Fuente: OCEPRE y Base de Datos IESA. En Hernandez et al (t999). & & & & &
\end{tabular}


La estructura de ingresos fiscales de la administración pública correspondiente al período 1990-1997 evidenció cierta volatilidad. Para 1990 los ingresos petroleros representaban el $82,9 \%$ del $\mathrm{fi}$ nanciamiento ordinario; paulatinamente, la contribución de los recursos de origen petrolero disminuyó considerablemente, ubicándose estos ingresos para los años 1996 y 1997 en $58,3 \%$ y $54,5 \%$ respectivamente. Asimismo, se destaca que para el año 1995 los ingresos no petroleros superaron a los ingresos de origen petrolero, $55,3 \%$ y $44,7 \%$ respectivamente. Ante la vulnerabilidad de la renta petrolera se orienta la recaudación de ingresos por otras fuentes principalmente de origen tributario, principalmente el Impuesto al Valor Agregado (IVA), es por ello que se busca la mejora de los sistemas de recaudación y de control implementados por el Sistema Nacional Integrado de Administración Tributaria (SENIAT) para disminuir la evasión fiscal e incrementar los niveles de recaudación ante la búsqueda de recursos urgentemente necesarios debido a la escasez de los mismos y así disminuir el déficit fiscal el cual se ha incrementado en cantidades exorbitantes, sobre todo en la década de los 90 .

Dentro de los ingresos no petroleros encontramos el Impuesto sobre la Renta (ISLR) el cual ha promediado cerca de $10 \%$ del total de los ingresos ordinarios para el período analizado. Paralelamente, con la recaudación del IVA que posteriormente fue llamado impuesto al consumo suntuario y ventas al mayor (ICSVM), la tributación indirecta ha tomado en palabras de Hernández et al (1999) un liderazgo creciente como fuente de financiamiento no petrolera, destacándo- se la participación del mismo y pasar de un $3,7 \%$ recaudado dentro del total de los ingresos ordinarios para el año 1993, que es cuando se implementó, a un $20,7 \%$ para el año 1997. Finalmente se destaca la participación del total de los impuestos indirectos dentro del total de los ingresos ordinarios del gobierno central los cuales se ubicaron para el año 1990 en un $6,4 \%$ para situarse posteriormente en el año 1997 en $34,1 \%$, destacándose la participación de los mismos para el año 1995 en $41,1 \%$. Por otra parte la renta aduanera ha contribuido para el periodo analizado entre un $7 \%$ y $9 \%$ del total de ingresos or. dinarios.

Dentro de este orden de ideas, los ingresos fiscales petroleros para el año 1998 disminuyeron considerablemente, así lo demuestra Purroy (1999) en su estudio que luego de la apertura petrolera para el año 1997 donde estos ingresos se ubicaron en un $13,3 \%$ del PIB, descendieron bruscamente hasta llegar a un $6,3 \%$ del PIB para el año 1998. En contraste para este año los ingresos no petroleros superaron a los ingresos petroleros situándose los mismos de acuerdo a este autor en un 10,3\% del PIB.

Esto se debe en palabras de Purroy (1999:7) a que los ingresos fiscales petroleros decrecieron durante el año 1998 en un $7 \%$ del PIB. La caída vertiginosa de los precios del petróleo en donde el precio promedio de la cesta de crudos venezolanos descendió de acuerdo a Purroy (1999:5) de $16,33 \$ /$ bl en 1997 a aproximadamente $10,70 \$ / \mathrm{bl}$ en 1998 , representó una caída de más del $50 \%$ en términos relativos. Esto, aunado a la decisión de la OPEP en el mes de octubre de 1997 de incrementar la producción alrededor 
de los 2,5 millones de barriles diarios, acentuó el problema de la sobreoferta de petróleo lo que los obligó posteriormente a recortar la producción por la acumulación de inventarios. El petróleo, que en 1997 representaba un $57 \%$ del total de los ingresos fiscales, aportó para el año 1998 apenas un $38 \%$ de los ingresos. Una caída tan brutal del aporte fiscal petrolero no se había visto nunca en la economía venezolana, ni siquiera en 1986.

\section{La estructura de ingresos de los estados en Venezuela}

La asignación de las competencias exclusivas como fuente de financiamiento al nivel intermedio de gobierno, es decir a los estados, parece ser apropiado. De acuerdo a Barrios (1998: 67) la asignación de la responsabilidad sobre estas competencias a los estados donde las mismas se localizan, permite internalizar los efectos externos positivos o negativos que se generen en la región, elevando asi la eficiencia en la utilización de recursos. Esto es asi específicamente en el caso de carreteras, autopistas, puentes, aeropuertos y puertos, cuyos beneficiarios no son exclusivamente los residentes del estado respectivo donde tales servicios se localizan, de alli a que el financiamiento se haga vía cargas a los usuarios de los mismos por lo que recae proporcionalmente sobre todos los beneficiarios.

Desde otra perspectiva, es decir desde la óptica política, siguiendo el estudio de Barrios (1998) poseer este tipo de competencias, es decir, su gestión en poder del gobierno regional estimula la ren- dición de cuentas por parte de las autoridades responsables de las mismas. Es decir que los gobernadores tengan que rendir cuentas a sus comunidades lo que incrementa la responsabilidad política y fiscal de sus dirigentes.

En el plano administrativo se tiene que la utilización de cargos a los usuarios en función del costo marginal de largo plazo de proveer el servicio, tiene la ventaja de que puede garantizar la sostenibilidad financiera del mismo, al mismo tiempo de facilitar la materialización de planes de expansión y mejoramiento de la calidad del servicio.

No obstante a pesar de todo lo anteriormente considerado, al apreciar el peso porcentual de estas fuentes de ingresos propios de los estados nos damos cuenta que las mismas representan un escaso potencial recaudatorio. Estos ingresos siguiendo el estudio de Barrios (1998) no llegan a un 2 por ciento de los recursos de las gobernaciones.

Los otros ingresos propios están constituidos específicamente por las reservas del tesoro regional, venta e intereses. Con respecto a las reservas del tesoro regional, las mismas incluyen ingresos no ejecutados del periodo anterior. Según Barrios (1998:69) estas deben ser descontadas de cualquier cáiculo de autonomía fiscal de los estados, ya que se nutren en una proporción importante de transferencias rezagadas provenientes del gobierno central, las cuales escapan al concepto de ingresos propios. En cuanto a los ingresos por venta de los bienes de los estados también se observa que su comportamiento es tan insignificante que tampoco pueden ser calificados como una fuente importante de recur- 
sos propios. A excepción de los procesos de privatización que en cualquier momento o período puede emprender el sector público, beneficiando asi a las gobernaciones en este rubro, en cualquier momento pudieran ser recursos bastantes significativos, pero esto es circunstancial.

El análisis de los recursos de los estados por concepto de intereses, resulta atractivo cuando se considera el monto de esos intereses devengados. Por lo anterior, se definen a los ingresos propios como la suma de los ingresos por competencias exclusivas, más las ventas (ordinarias y extraordinarias), más los intereses devengados (ordinarios y extraordinarios), más otros ingresos propios.

Con un subtotal de ingresos propios que no llega a superar ni un 10 por ciento de la estructura de financiamiento de los estados (incluyendo aquí los ingresos extraordinarios por venta y recursos por intereses devengados), es difícil que las gobernaciones puedan lograr cierto margen de autonomía financiera para financiar su propio gasto y realizar costosas inversiones públicas (Tabla 2).

Ante esta situación, luce necesario pensar en evaluar la posibilidad de crear nuevas fuentes de financiamiento para los estados, de conferir nuevas potestades tributarias a los estados o pensar en la coparticipación tributaria de algunos impuestos que hoy en día están bajo potestad del gobierno central.

Las transferencias intergubernamentales vienen a cumplir el rol de instrumento de equilibrio fiscal de la nece- saria correspondencia entre competencias de gastos asignada a estos estados y sus necesidades de recursos financieros para atender estas responsabilidades bajo un contexto de una economia sesgada por un escaso rendimiento recaudatorio de sus propias fuentes de financiamiento.

Se puede citar a países como España, donde las transferencias intergubernamentales alcanzan un 79 por ciento. Esto con la finalidad de afirmar que las transferencias intergubernamentales no son dañinas como se piensa en algunos países, sino que dependerán de como estas estén diseñadas y de los objetivos que persiga cada país. Las mismas persiguen el equilibrio vertical entre los distintos niveles de gobierno, pero además también intentan disminuir los desbalances horizontales dentro de un mismo nivel de gobierno. Por lo tanto se destaca su importancia dentro de un sistema de relaciones fiscales intergubernamentales.

A pesar de que el situado constitucional sigue representando la principal fuente de financiamiento de los estados, ha venido perdiendo peso en la estructura de ingresos de la mayoría de los gobiernos regionales desde que se dio inicio al proceso de descentralización en Venezuela. Para el año 1990 los estados dependian en un $98.5 \%$ de este mecanismo de transferencia intergubernamental, no asi para el año 1999 donde disminuye esta dependencia considerablemente, ubicándose en un $63.3 \%$. Además se destaca la significativa menor importancia que se registra 


\section{Tabla 2}

\section{Estructura de Ingresos de los Estados} (\% del total de ingresos)

\begin{tabular}{lrrrrrrrrrr}
\hline Concepto & 1990 & 1991 & 1992 & 1993 & 1994 & 1995 & 1996 & 1997 & 1998 & 1999 \\
\hline Situado & 98.5 & 95.2 & 94.8 & 92.7 & 81.6 & 83.9 & 71.8 & 58.5 & 60.4 & 63.3 \\
Asignaciones Económicas & - & - & - & - & - & - & - & 2.3 & 10.4 & 10.7 \\
$\begin{array}{l}\text { Especiales } \\
\text { FIDES }\end{array}$ & - & - & - & - & - & - & 4.6 & 5.8 & 8.6 & 8.9 \\
Contribución & 1.1 & 0.7 & 1.7 & 2.6 & 9.3 & 12.9 & 22.2 & 31.8 & 18.8 & 15.7 \\
Servicios & & & & & & & & & & \\
Otras Transferencias & 0 & 0 & 0 & 3.2 & 8 & 10.3 & 0 & 0 & 0 & 0 \\
Total Tranferencias & 99.6 & 95.9 & 96.5 & 95.3 & 90.9 & 96.8 & 98.7 & 98.5 & 98.1 & 98.5 \\
Ingresos Propios & 0.4 & 4.1 & 3.5 & 4.7 & 9.1 & 3.2 & 1.3 & 1.5 & 1.9 & 1.5 \\
\hline
\end{tabular}

Fuente: OCEPAE. (1999).

para el caso de algunos estados que se encuentran con un notable mayor avance en este proceso ${ }^{2}$.

El cambio en la estructura de financiamiento del gobierno central responde básicamente a la búsqueda de ingresos de origen interno, los cuales son menos volátiles o más estables que los ingresos ordinarios de origen petrolero. Estos ingresos de origen interno corresponden a el impuesto al valor agregado, así como la recaudación tributaria sobre las rentas de otras actividades ya sean estas personales o corporativas.

Asimismo, como consecuencia de una intensificación en el uso de los recursos del FIDES, así como también por la incorporación de la Ley de Asignaciones Económicas Especiales, las fuentes de fi- nanciamiento disponibles para los estados se ha diversificado via transferencias intergubernamentales.

EI FIDES se nutre principalmente de los recursos que la nación recauda por concepto del Impuesto al Valor Agregado que de acuerdo a la ley que lo regula, el porcentaje a asignarse a los estados oscila entre un 15 y $20 \%$. Desde el inicio del gobierno del Presidente Hugo Chávez en el año 1999 este porcentaje se ubica en su nivel más bajo. No obstante, el FIDES también podrá obtener recursos provenientes de organismos internacionales para proyectos específicos y en los programas de cooperación técnica y cualquier otro recurso que le sea asignado de acuerdo al ordinal 7 del artículo 2 de la ley que lo rige.

2 Este notable avance del proceso de descentralización se aprecia por ejemplo en los Estados Zulia y Carabobo ya que presentan ventajas comparativas con respecto a otros estados. El Estado Zulia hizo efectiva la transferencia de todas sus competencias exclusivas, destacándose la del Puente General Rafael Urdaneta y el Puerto de Maracaibo. Carabobo también presenta la ventaja de poseer la Autopista Regional. 
Por su parte las Asignaciones Económicas Especiales tienen como referencia los ingresos obtenidos por el Poder Nacional producto de la explotación de las minas e hidrocarburos, ingresos que este nivel de gobierno asume con exclusividad.

Por lo anterior consideramos que la estructura de financiamiento en Venezuela está altamente centralizada y registra un pronunciado sesgo hacia las transferencias intergubernamentales, las cuales representaron en promedio para el período 1990-1999 un 96.8 por ciento de las entradas de los recursos fiscales de los estados. Existe una marcada asimetría representada por el aumento de los ingresos por esta vía, en desmedro de los ingresos propios, los cuales no superan el 10 por ciento. Asimismo, si solo hacemos referencia a los ingresos propios vía competencia exclusiva, no logran representar según Barrios (1998) ni un 2 por ciento en esta estructura de financiamiento, por lo que lo consideramos en este estudio de bajo impacto fiscal para los estados (Tabla 2).

A pesar de haber disminuido en los estados la dependencia de los ingresos del situado constitucional, el cual representó para el año 1997 el $58.5 \%$ del total de la estructura de los ingresos de los estados, $60.4 \%$ para 1998 , y 63,3 para el año 1999 respectivamente, este sigue representando la principal fuente de financiamiento de los gobiernos regionales. No obstante, la referida disminución de esta dependencia se debe al aumento de la participación porcentual en la estructura de ingresos del FIDES y la LAEE, la cual se ubicó para el año 1999, en $8.9 \%$ y $10.7 \%$ respectivamente (Tabla 2 ).

\section{Transferencias intergubernamentales e ingresos propios: la combinación óptima para los estados}

Existe según De La Cruz (1998) un amplio consenso en la literatura básica sobre federalismo fiscal, en lo referente a la conveniencia de combinar los recursos tributarios propios de los gobiernos subnacionales con las transferencias automáticas e incondicionadas del gobierno central. En general se parte de la idea de que las transferencias deben ser guiadas por criterios simples y transparentes, impidiendo de esta manera la negociación entre los distintos niveles intergubernamentales como mecanismo de asignación.

Por otra parte, otro autor McLure (1999) plantea la necesidad de una asignación racional de las atribuciones impositivas, ya que favorece a que cada nivel del gobierno pueda ejercer control sobre su destino fiscal. Asimismo, permite elegir el nivel de gasto público para cada nivel de gobierno. Para ello, la asignación tributaria debe contar con un margen considerable de ingresos propios, sugiere este autor, que la asignación tributaria racional ayuda a mejorar la rendición de cuentas donde la competencia tributaria entre las jurisdicciones subnacionales puede ejercer algunos efectos positivos ya que en materia de impuestos se protege a los ciudadanos de la explotación por sus políticos y burócratas, así como también que los contribuyentes que pagan sus impuestos reciban los servicios respectivos. No obstante, para Shah (1997:2) la rendición de cuentas se ve obstaculizada en la mayoría de los países 
en vías de desarrollo, ya que los gobiernos subnacionales tienen acceso restringido a sus propias bases impositivas, dependiendo así, de las transferencias procedentes del gobierno central.

De acuerdo a McLure (1999:8) un determinado impuesto debe asignarse al nivel más bajo del gobierno que tenga la capacidad de implantarlo y para el cual sea apropiado. Asimismo, destaca dicho autor, la importancia de este principio al señalar que el cumplimiento del mismo, minimizaría la tendencia hacia el desequilibrio vertical, el cual se presenta por la dificultad que tienen los gobiernos subnacionales para administrar muchos impuestos, a diferencia del gobierno nacional, el cual puede ejecutar la mayoría de los impuestos asignados a un nivel inferior de gobierno.

Dentro de éste mismo orden de ideas, De La Cruz (1998) plantea en su investigación que los impuestos con base tributaria móvil en todo el territorio del país y los que tienen un fuerte potencial redistributivo deben ser nacionales, los de base de movilidad limitada: regionales y los de base fija: locales. Como ejemplo de lo anterior, sería el impuesto al valor agregado (IVA), el cual es de base altamente móvil, por lo tanto sería competencia del Poder Nacional. Otro impuesto de ésta competencia sería el impuesto sobre la renta a las empresas. El impuesto sobre la renta personal, por el contrario, debería ser administrado por los estados y los impuestos sobre la propiedad inmobiliaria, automóviles, cobro de tarifas por servicios públicos locales, serían competencia de los municipios.
A pesar de los supuestos anteriormente considerados, De La Cruz (1998) afirma que existe escaso acuerdo sobre las proporciones de la combinación óptima entre transferencias intergubernamentales y competencias tributarias subnacionales. Sin embargo, al plantearse la interrogante sobre, ¿cuál debería ser la mezcla óptima entre transferencias e impuestos locales?, el autor aqui considerado plantea que el grado óptimo de mezcla sería aquél que permitiera la mayor cantidad de ingresos propios a los gobiernos locales, buscando siempre la eficiencia fiscal y al mismo tiempo maximice la alineación macroeconómica de los diferentes niveles intergubernamentales, no obstante, advierte que no hay una respuesta universal, ya que dependerá altamente de las condiciones institucionales que le son especificas a cada país.

A mayor transferencias por parte del gobierno central a los gobiernos subnacionales se produce una mayor alineación de éstos últimos a las políticas y objetivos macroeconómicos del gobierno central. Por el contrario, si los gobiernos subnacionales obtienen una mayor cantidad de ingresos propios, sin mayores ataduras a las transferencias, la alienación a los objetivos macroeconómicos del gobierno central es mucho menor.

Asimismo, cuanto más ingresos propios generen los gobiernos subnacionales y mayor sea su grado de autonomía fiscal, más podrán afectar e influir en las condiciones macroeconómicas de un país. No obstante, estos ingresos deben balancearse con transferencias desde el gobierno central. Este argumento resulta 
conveniente por razones de equidad entre las regiones, así como también, para lograr el equilibrio macroeconómico.

Los gobiernos subnacionales de acuerdo a McLure (1999:7), deben contar con ingresos propios suficientes para así financiar los servicios públicos que prestan. Asimismo señala el autor que si un gobierno subnacional legisla y recauda sus propios impuestos, respaldado por garantías constitucionales significativas de su derecho respectivo, está claro que tiene una fuente de ingresos propios. Si el gobierno subnacional recibe transferencias del gobierno nacional, pero las mismas se encuentran determinadas de manera objetiva y están asimismo garantizadas por la constitución respectiva, es razonable a juicio de este autor, que ese nivel de gobierno tiene ingresos propios. Sin embargo, advierte que si se hacen éstas transferencias en forma ad hoc, es decir, a discreción del gobierno nacional, de forma arbitraria e impredecible, es posible que no existan ingresos propios para el nivel de gobierno considerado. Este autor, también considera como ingresos propios los impuestos compartidos y los impuestos gravados como adicionales sobre lo recaudado por el gobierno nacional.

\section{La descentralización fiscal en la Constitución de 1999}

El 15 de diciembre del año 1999 a través de un referendo consultivo al pueblo venezolano es aprobado el proyecto de Constitución elaborado por la Asamblea Nacional Constituyente, justificado por el actual Presidente de la República Hugo Chávez Frías porque la Constitución de 1961 representa el mo- delo económico y político del Pacto de Punto Fijo, así como también al modelo paternalista, clientelar y de partido. Estos son sólo algunos de los argumentos que llevaron a la Asamblea Nacional Constituyente a redactar en tiempo record una nueva Constitución. Pero ¿qué tiene de novedad esta nueva Constitución en materia de descentralización fiscal para los estados?, ¿se fortalece o se debilita éste proceso?, ¿se le transfieren a los estados nuevas competencias dentro del ramo tributario?. A continuación se examinarán los artículos que hacen referencia a esta materia con la finalidad de identificar tendencias.

En lo referente al modelo de Estado, la nueva Constitución contempla en su artículo 4 que la República Bolivariana de Venezuela es un Estado federal descentralizado, además de regirse por los principios de cooperación, solidaridad y corresponsabilidad. Asimismo en el preámbulo de la misma se especifica que la sociedad venezolana es democrática, participativa y protagónica.

Un artículo reaimente innovador contemplado en la nueva carta magna, si la comparamos con la Constitución de 1961, es el artículo 158 donde la descentralización adquiere rango constitucional. El mismo reza lo siguiente: "La descentralización, como política nacional, debe profundizar la democracia, acercando el poder a la población y creando las mejores condiciones, tanto para el ejercicio de la democracia como para la prestación eficaz y eficiente de los cometidos estatales".

El anterior artículo se constituye en un gran avance para el proceso de descentralización y en el mismo se contem- 
conveniente por razones de equidad entre las regiones, así como también, para lograr el equilibrio macroeconómico.

Los gobiernos subnacionales de acuerdo a McLure (1999:7), deben contar con ingresos propios suficientes para asi financiar los servicios públicos que pres$\tan$. Asimismo señala el autor que si un gobierno subnacional legisla y recauda sus propios impuestos, respaldado por garantías constitucionales significativas de su derecho respectivo, está claro que tiene una fuente de ingresos propios. Si el gobierno subnacional recibe transferencias del gobierno nacional, pero las mismas se encuentran determinadas de manera objetiva y están asimismo garantizadas por la constitución respectiva, es razonable a juicio de este autor, que ese nivel de gobierno tiene ingresos propios. Sin embargo, advierte que si se hacen éstas transferencias en forma ad hoc, es decir, a discreción del gobierno nacional, de forma arbitraria e impredecible, es posible que no existan ingresos propios para el nivel de gobierno considerado. Este autor, también considera como ingresos propios los impuestos compartidos y los impuestos gravados como adicionales sobre 10 recaudado por el gobierno nacional.

\section{La descentralización fiscal en la Constitución de 1999}

El 15 de diciembre del año 1999 a través de un referendo consultivo al pueblo venezolano es aprobado el proyecto de Constitución elaborado por la Asamblea Nacional Constituyente, justificado por el actual Presidente de la República Hugo Chávez Frías porque la Constitución de 1961 representa el mo- delo económico y político del Pacto de Punto Fijo, así como también al modelo paternalista, clientelar y de partido. Estos son sólo algunos de los argumentos que llevaron a la Asamblea Nacional Constituyente a redactar en tiempo record una nueva Constitución. Pero ¿qué tiene de novedad esta nueva Constitución en materia de descentralización fiscal para los estados?, ¿se fortalece o se debilita éste proceso?, ¿se le transfieren a los estados nuevas competencias dentro del ramo tributario?. A continuación se examinarán los artículos que hacen referencia a esta materia con la finalidad de identificar tendencias.

En lo referente al modelo de Estado, la nueva Constitución contempla en su artículo 4 que la República Bolivariana de Venezuela es un Estado federal descentralizado, además de regirse por los principios de cooperación, solidaridad y corresponsabilidad. Asimismo en el preámbulo de la misma se especifica que la sociedad venezolana es democrática, participativa y protagónica.

Un artículo realmente innovador contemplado en la nueva carta magna, si la comparamos con la Constitución de 1961, es el artículo 158 donde la descentralización adquiere rango constitucional. El mismo reza lo siguiente: "La descentralización, como política nacional, debe profundizar la democracia, acercando el poder a la población y creando las mejores condiciones, tanto para el ejercicio de la democracia como para la prestación eficaz y eficiente de los cometidos estatales".

El anterior artículo se constituye en un gran avance para el proceso de descentralización y en el mismo se contem- 
de la generación de ingresos propios, de alli a que exista un fuerte contraste entre el artículo que le otorga rango constitucional al proceso de descentralización y todo lo anteriormente especificado en materia de ingresos en poder del Gobierno Central.

El rasgo centralizador de la nueva Constitución se afianza aún más cuando la misma especifica que quedará en poder del nivel superior de gobierno el régimen del transporte nacional, de la navegación y del transporte aéreo, terrestre, marítimo, fluvial y lacustre; de los puertos, aeropuertos y su infraestructura, además del sistema de vialidad nacional.

La posibilidad que tenian los estados a través del endeudamiento subnacional se ve severamente limitada por cuanto la nueva Constitución también se reserva la potestad en materia de crédito público. Los estados como vía para ampliar sus fuentes de financiamiento, podian fortalecer su mercado de capitales y pensar a futuro en la emisión de bonos a este nivel subnacional, pero esta opción no se materializó en la Constitución de 1999, muy al contrario quedó eliminada.

El abanico de opciones se ha restringido, por lo que los estados no tienen más alternativa, sino esperar a que sean transferidas nuevas competencias de indole tributaria a futuro mediante el artículo 157 donde se expresa que la Asamblea Nacional, por la mayoría de sus integrantes, le podrá atribuir a los estados determinadas materias de la competencia nacional, a fin de promover la descentralización.

Las competencias exclusivas transferidas desde el Poder Central a los Estados de acuerdo al artículo 11 de la Ley Orgánica de Descentralización que- daron delimitadas en el artículo 164 de la Constitución de 1999, solo se le agrega una nueva competencia exclusiva en materia de timbres y estampillas, quedando las otras competencias inalteradas, estas son: ostrales de perlas y minerales no metálicos, las salinas, papel sellado, vías estadales e interestadales, así como también la competencia de los puertos y aeropuertos, pero como ya se demostró en este estudio que las mismas son de bajo impacto fiscal.

Se destaca, asimismo, en el ordinal 3 del mencionado artículo como competencia exclusiva de los estados, la inversión y administración de sus recursos, incluso de los provenientes de las transferencias, así como aquellos que se les asignen como participación en los tributos nacionales. Por lo anterior se deduce que se pueden ceder a los estados ciertos tributos desde el Poder Nacional a través de la coparticipación tributaria. Esto es un aspecto positivo pero dependerá del previo consenso nacional y de la Asamblea Nacional.

También se contempla en el ordinal 4 del articulo en referencia, que es de la competencia exclusiva de los estados la organización, recaudación, control y administración de los ramos tributarios propios, pero no está claro cuáles son estos tributos, ya que los de mayor impacto fiscal están en poder del Gobierno Nacional.

En el artículo 167 de la Constitución de 1999 se detallan los ingresos de los estados los cuales lucen insignificantes, ya que se remiten principalmente a los recursos por concepto de situado constitucional. Es lamentable que en este aspecto no se hayan introducido innovaciones con respecto a la Constitución de 
1961. Se mantienen los mismos criterios para distribuir estos recursos en base a la población. No se manejó la posibilidad de considerar un indice de necesidades insatisfechas o considerar un indice de esfuerzo fiscal en la fórmula del situado.

Asimismo los estados deben en cada ejercicio fiscal destinar un minimo del cincuenta por ciento del total de los ingresos ordinarios para la inversión. A criterio de Sánchez Meleán (2000) resulta conveniente acabar con la incondicionalidad del Situado, esto se trasladó de la Constitución de 1961 a la de 1999. El término inversión incluido en el texto constitucional resulta ambiguo. ¿Será equivalente al término gasto en general o, implica una orientación del gasto hacia determinados tipos de bienes?

Un aspecto positivo que dependerá siempre del consenso nacional y de la voluntad de la Asamblea Nacional es lo contemplado en el ordinal 5 del artículo 167 el cual reza lo siguiente: "Son ingresos de los Estados los demás impuestos, tasas y contribuciones especiales que se les asigne por ley nacional, con el fin de promover el desarrollo de las haciendas públicas estadales".

En efecto la Disposición Transitoria Cuarta de la nueva Carta Magna, en su numeral sexto contempla que la Asamblea Nacional dentro del primer año, contado a partir de su instalación aprobará una ley que desarrolle la hacienda pública estadal, estableciendo los tributos que la componen, los mecanismos de su aplicación y las disposiciones que la regulen de acuerdo a los principios y normas de esta Constitución.

Lo anterior se constituye en un importante avance en materia de hacienda pública para los estados, ya que se puede pensar por esta vía en la transferencia de importantes tributos desde el poder central hacia los estados tales como: la coparticipación del impuesto sobre sucesiones y donaciones, el impuesto sobre la renta para personas naturales y el impuesto al valor agregado. Asimismo, se podrán ceder el impuesto de licores y cigarrillos, el impuesto al consumo de la gasolina y otros derivados, impuestos específicos al consumo, entre otros. Todo lo enumerado anteriormente se constituye en alternativas viables que pueden traducirse en ingresos propios para los estados y asi lograr una mayor autonomia $y$ responsabilidad fiscal de los mismos para financiar su propio gasto.

Como figura institucional se crea de acuerdo al artículo 185 de la Constitución de 1999, el Consejo Federal de Gobierno, el cual será el órgano encargado de la planificación y coordinación de políticas y acciones para el desarrollo del proceso de descentralización y transferencia de competencias del Poder Nacional a los Estados y Municipios. Estará presidido por el Vicepresidente Ejecutivo e integrado por los Ministros, gobernadores, un alcalde por cada Estado y por representantes de la sociedad organizada. De este Consejo dependerá el Fondo de Compensación Interterritorial, contemplado en el ordinal 6 del artículo 167 como ingreso de los estados y el mismo estaria destinado al financiamiento de inversiones públicas orientadas a promover el desarrollo equilibrado de las regiones, favoreciendo así a las regiones con menor desarrollo. Una función primordial de este Consejo, con base en los desequilibrios regionales, seria discutiry 
aprobar anualmente los recursos que se dirigirán a este fondo.

Finalmente, el éxito del proceso de descentralización fiscal en Venezuela dependerá del consenso nacional para poder transferirle a los estados ciertos tributos. Están presentes en la Constitución del 1999 los mecanismos necesarios para poder dotar a los estados de los ingresos propios que tanto requieren para poder flexibilizar y equilibrar sus finanzas públicas. A corto plazo la Constitución analizada no deja de ser centralista al tener en su poder los principales ramos tributarios de mayor impacto fiscal. A mediano plazo están sentadas las bases en la nueva Constitución para dotar a los estados de nuevos ingresos propios.

\section{Conclusiones}

En Venezuela en los últimos años se ha venido dando un cambio en la estructura de ingresos de los estados, es decir, el Situado Constitucional sigue representando la principal fuente de financiamiento de los mismos, pero este mecanismo ha venido perdiendo peso en esta estructura desde que se dio inicio al proceso de descentralización. Para el año 1989, representaba para los estados el 97 por ciento del total de sus ingresos. No obstante, para el año 1998 se ubicó alrededor de un 60.4 por ciento.

Como se puede apreciar la dependencia del situado es mucho menor, pero esto es debido al uso de los recursos del Fondo Intergubernamental para la Descentralización y del Sistema de las Asignaciones Económicas Especiales para los Estados Mineros y Petroleros como nuevos mecanismos de trans- ferencias intergubernamental que tienen los estados.

En referencia a los ingresos propios, los mismos se expresan básicamente a través de lo generado por concepto de transferencias exclusivas. Como se observó en este estudio estas competencias son de bajo impacto fiscal para los estados representando solamente un escaso $2 \%$ de los recursos. Si se incluyen en este rubro a los ingresos extraordinarios por ventas y recursos por intereses devengados, estos ingresos propios no llegan a representar ni un 10\% en esta estructura de financiamiento.

Es de hacer notar que, de acuerdo a la literatura estudiada, las transferencias intergubernamentales no son perjudiciales, naturalmente la forma especifica que ellas toman y su importancia en el financiamiento de la gestión de los estados, dependerán de las condiciones politicas, institucionales, culturales y económica que ha lo largo de su historia las van conformando como instrumentos de politica pública. Sin embargo hay que aclarar que en la medida en que la mayoria del financiamiento de la gestión pública en los estados no depende de fuentes propias de financiamiento, sino de estas transferencias, se debilita la relación fiscal entre autoridades y comunidades regionales.

La estructura de los ingresos de los estados en Venezuela está altamente centralizada. Sin embargo en la nueva Constitución se contemplan novedosos mecanismos para descentralizar ciertos tributos, tal es el caso de la posibilidad de crear para los estados la hacienda pública estadal. Esta seria la vía para que el Poder Central le transfiera a los estados ciertos tributos de mayor impacto fiscal, 
pero esto dependerá del previo consenso nacional y de la voluntad política de la Asamblea Nacional.

De lo anterior se desprende la necesidad que tienen los estados de tener una asignación racional de atribuciones impositivas, ya que un determinado impuesto debe asignarse al nivel más bajo del gobierno que tenga la capacidad de implantarlo y para el cual sea apropiado. Esto con la finalidad de disminuir el desequilibrio vertical existente en la estructura de ingresos de los estados en Venezuela. Para tales fines, los impuestos que se prestan para ser transferidos desde el Poder Nacional a los Estados serian: la coparticipación del impuesto sobre sucesiones y donaciones; del impuesto sobre la renta para personas naturales y del impuesto al valor agregado. Asimismo, se podrán ceder con exclusividad, además de los ya contemplados en la Constitución de 1999, el impuesto de licores y cigarrillos, el impuesto al consumo de la gasolina y otros derivados, impuestos específicos al consumo, entre otros. Lo importante es la búsqueda de fuentes alternativas de financiamiento para los estados para lograr un equilibrio armónico entre transferencias e ingresos propios.

\section{Bibliografía citada}

Asamblea Nacional Constituyente (1999). Constitución de la República Bolivariana de Venezuela. Gaceta oficial $N$ 36.860.30 de Diciembre. Editada por Discolar. Caracas.

Barrios, Armando (1996). "Descentralización Fiscal y Estabilización Macroeconómica en Venezuela". Ponencia presentada en el III Seminario Internacional de Descentralización Fiscal en
América Latina: Nuevos Desafios y Agenda de Trabajo. CEPALGTZ. Isla de Margarita del 2 al 4 de Octubre.

Barrios, Armando (1998). "Las Finanzas Públicas de los Estados en Venezuela". En: Descentralización en Perspectiva. Rafael de la Cruz (Compilador). Ediciones IESA. Caracas.

Comisión Legislativa Nacional (2000).Ley que crea el Fondo Intergubernamental para la Descentralización (FIDES). Gaceta Oficial N 37.022. 25 de Agosto. Ediciones Dabosan, C:A. Caracas.

Congreso de la República de Venezuela (1989). Ley Orgánica de Descentralización, Delimitación y Transferencia de Competencias del Poder Público. Editorial Eduven. Caracas.

De La Cruz, Rafael (1998). "La Revoluclón Federal de las Finanzas Públicas" En Descentralización en Perspectiva. Ediciones IESA. Caracas.p.1-50.

Hernández, Angel; Barrios, Armando; Broitman, Lily; De la Cruz, Rafael; Mascareño Carlos $Y$ Rachadell Manuel (1999).La Descentralización Diálogo para el Desarrollo. Proyecto del Programa de las Naciones Unidas para el Desarrollo, Banco Mundial y Banco Interamericano de Desarrollo. Editorial. Nueva Sociedad: segunda edición. Caracas.

McLure, Charles.(1999). "El Problema de la Asignación Tributaria: Consideraciones Conceptuales y Administrativas para lograr la Autonomía Fiscal Subnacional". Mimeo. Banco Mundial. Washington, D. C.

Oficina Central de Presupuesto (1999). Exposición de Motivo del Proyecto de Presupuesto.

Purroy, Miguel (1999). "Balance Económico 1998, perspectivas para 1999". En Fevista SIC. Centro Gumilla. Enero Febrero 1999. Año LXII, L 611. Caracas. 
Shah, Anwar (1997). "Reforma de las Relaciones Fiscales Intergubernamentales en las Economías de los Países en Vias de Desarrollo y de Mercados Emergentes". En: Serie sobre Políticas Investigación. Segunda impresión. The World Bank. Washington, D. C.
Sánchez Meleán, Jorge (2000). "La Descentralización Fiscal y la Ley de Hacienda Pública Estadal". Ponencia presentada en el foro La Hacienda Pública Estadal: Una Promesa que la Provincia Exige. La Universidad del Zulia- Rectoría. Realizado el 18 de mayo. Maracaibo. Mimeo. 